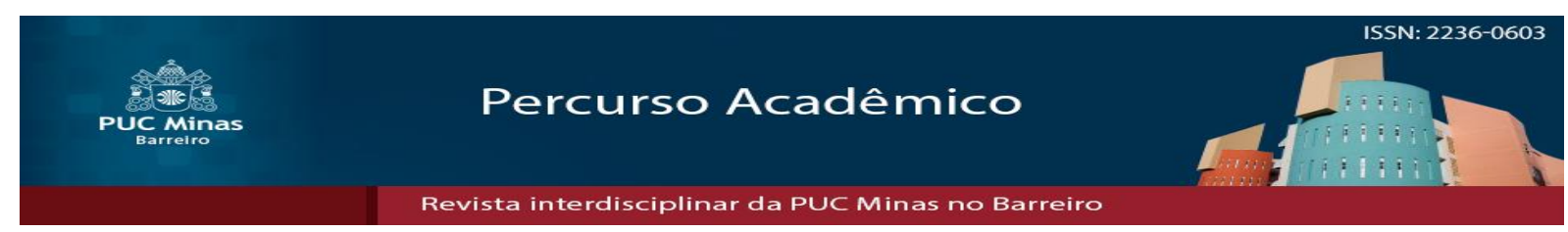

\title{
Novas tecnologias e relações de trabalho: cyberbullying, responsabilidade patronal e reforma trabalhista
}

\section{New Technologies and work relationships: cyberbullying, employer's responsibility and labour reform}

\author{
Denise Pires Fincato ${ }^{1}$ \\ Leiliane Piovesani Vidaletti ${ }^{2}$
}

\section{Resumo}

A pesquisa enfrenta a temática do cyberbulling nas relações de trabalho, não sem antes superar a questão semântica de sua conceituação, partindo dos termos bullying e cyberbullying e chegando ao usualmente empregado nas relações laborais "assédio moral" e "assédio sexual". Examina a Lei de "combate à intimidação sistemática" - Lei $\mathrm{n}^{\mathrm{o}}$. 13.185/15, verificando sua aplicabilidade (e utilidade) no ambiente laboral - bem como o sistema de responsabilidade aplicado aos casos de assédio moral e sexual perpetrados em ambientes de trabalho. Investiga acerca da adequação da aplicação da Lei $\mathrm{n}^{\mathrm{o}}$. 13.185/15 no cenário trabalhista, notadamente no que se refere à responsabilidade do empregador pela manutenção de ambiente laboral hígido e adequado, identificando hipóteses em que possa ser responsabilizado por danos aos trabalhadores, especialmente quando os atos de violência se derem em espaços virtuais, mas com reflexos concretos na saúde e psiquè dos trabalhadores. Por fim, enquadra a responsabilidade do empregador na nova moldura da responsabilidade civil da Lei da Reforma Trabalhista, abordando especiais detalhamentos.

Palavras-chave: Bullying. Cyberbullying. Assédio moral. Responsabilidade do empregador. Reforma trabalhista.

Artigo recebido em 27 de Junho de 2017 e aprovado em 18 de Março de 2019

1 Pós-Doutora em Direito do Trabalho pela Universidad Complutense de Madrid. Doutora pela Universidad de Burgos. Professora Pesquisadora no PPGD-PUCRS, coordenadora do Grupo de Pesquisas Novas Tecnologias, Processo e Relações de Trabalho (NTPRT - PUCRS/CNPq). Advogada e Consultora em Souto, Correa, Cesa, Lummertz e Amaral Advogados. E-mail: dpfincato1@ gmail.com.

2 Doutoranda pela Pontifícia Universidade Católica do Rio Grande do Sul - PUCRS. Mestre pela Pontifícia Universidade Católica do Rio Grande do Sul - PUCRS. Integrante do Grupo de Pesquisas Novas Tecnologias, Processo e Relações de Trabalho. Advogada, professora e palestrante. E-mail: leilividaletti@yahoo.com.br. 


\begin{abstract}
This research faces the issue of cyberbullying in work relations not without overcoming the semantics matter of its concept, starting from the terms "bullying" and "cyberbullying" and ending up at the commonly used expressions in labour relations "psychological harassment" and "sexual harassment". The research considers the Law of "fighting against systematic intimidation" - Law $\mathrm{n}^{\circ}$. 13.185/15, verifying its applicability (and usability) in labour environment - as well as the responsibility system applied to the cases of sexual and psychological harassment perpetrated in work environments. This research investigates on adequacy of Law No. 13.185/15 implementation in the labour scenario, notably in what concerns to the employer's responsibility to maintain a salubrious and appropriate labour environment, identifying hypotheses where they can be liable for damages to the workers, especially when the acts of violence happen in virtual spaces but cause concrete reflections to the health and psyche of workers. Finally, the present research frames the employer's responsibility in the new civil responsibility framework of Labour Reform, approaching special detailing of the scenario that even not being approved reveals room for juridical, economic and social contemporary debates.
\end{abstract}

Keywords: Bullying. Cyberbullying. Psychological harassment. Employer's responsibility. Labour reform.

\title{
1 Introdução
}

As relações humanas nem sempre são fraternas e respeitosas. Sua dinâmica leva a momentos de equilíbrio e desequilíbrio, harmonia e conflito. Estabilizar o fiel da balança é fator determinante para a manutenção da saúde dos que se relacionam e da higidez do ambiente que habitam. A pedagogia e a psiquiatria estudam diversos fenômenos comportamentais, analisando suas causas e reflexos nas relações humanas: o bullying e o assédio moral, por exemplo, foram observados primeira e respectivamente por estas áreas do saber.

É inegável o impacto das tecnologias de comunicação no comportamento humano, especialmente numa amostra urbana, jovem e trabalhadora. Este estudo inicia rememorando os desvios comportamentais comuns em ambientes escolares, que recebem a designação técnica de bullying e que, quando invadem o espaço virtual e/ou utilizam-se de ferramentas digitais, passam a chamar-se de cyberbullying, inegavelmente potencializando seu alcance e efeitos.

A questão do bullying é tão cotidianamente grave, quase epidemiológica, que provocou edição de legislação própria no Brasil, a Lei no 13.185 de 2015, denominada "Programa de Combate à Intimidação Sistemática", espécie de denominação genérica, que pretende abarcar estratégias para prevenir e atacar as diversas formas de violência repetida com finalidade intimidatória e aterrorizadora, especialmente em âmbito escolar, 
mas não exclusivamente neste, como se aponta neste estudo. O cyberbullying é previsto em tal lei como uma das possíveis manifestações do bullying.

Neste estudo, que possui viés trabalhista, o cyberbullying (fenômeno originariamente identificado nas relações entre escolares) é transportado às relações de trabalho lato senso, testando-se a responsabilidade patronal e verificando-se em que pode agir o empregador especialmente no sentido de precaver-se, mantendo a boa ambiência laboral.

O estudo realiza-se de forma hipotético-dedutiva, operando-se a partir de métodos de procedimento histórico-comparativo, estruturalista e funcionalista, além de guiar-se pela interpretação sistemática. A pesquisa é essencialmente bibliográficodocumental.

A coleta de dados iniciou em período em que se discutia acerca de reformas na Consolidação das Leis do Trabalho (tramitação do PLC $n^{\circ}$ 38/2017), tendo sido concluída - para fins de escrita deste ensaio - dentro do atual contexto de vigência da Lei ${ }^{\circ} 13.467$, de 13 de julho de 2017, que provocou alterações profundas no campo do direito material do trabalho, especialmente no que toca à responsabilidade por danos extrapatrimoniais, ponto sensível que será abordado na pesquisa e sobre o qual pretendem as autoras contribuir ao estudo e aprofundamento.

\section{Do bullyng ao cyberbullyng: tecnologia e terror psicológico na relação de trabalho}

A palavra bullying tem origem no termo inglês bull, sendo traduzida para nosso idioma pela palavra "touro". O acréscimo da letra $y$ ao vocábulo forma o adjetivo bully, que significa "valentão, brigão, tirano". A partir dessas duas palavras, surgiu a expressão bullying para referir-se ao ato de intimidar, amedrontar, tiranizar e aterrorizar pessoas. É pertinente ressaltar, ademais, que a menção ao touro remonta à compleição física do animal, de porte amedrontador e intimidador, que subjuga sua vítima física e psicologicamente (MELO, 2011, p. 21).

Não há dúvidas de que o bullying é uma forma de violência e, afora a nomenclatura, não é novidade. Por violência, fenômeno polissêmico e multicasual, pode-se observar diferentes modalidades e níveis, a partir de distintas perspectivas (ROCHA, 2012, p. 20). Sendo assim, é fácil perceber que a violência não se configura apenas em agressões físicas, que deixam marcas aparentes nas vítimas, mas em agressões de ordem moral, que podem ocasionar dor e sofrimento, com sequelas psicológicas, transitórias ou permanentes.

A violência, ademais, pode se dar em contextos diversificados, como o doméstico, escolar, ou de trabalho; ainda, em momentos distintos da vida: infância, adolescência ou fase adulta; também, em relação a certos grupos, como, por exemplo, em face da mulher ou de determinadas raças ou credos.

Em razão de todas as nuances acima apontadas, a definição de violência é tarefa assaz árdua, que também vai sofrer influência do momento histórico e do contexto social em que inserida. Nessa toada, opta-se, diante da diversificada gama de conceitos, 
pela definição adotada pela Organização Mundial de Saúde - OMS, no Informe Mundial sobre la violência y la salud, que se revela de forma mais abrangente, incluindo no conceito de violência tanto a ameaça quanto o uso efetivo de força física, desde que com probabilidade de causar lesões, morte, danos psicológicos, transtornos ou privações contra outra pessoa, grupo ou comunidade (ORGANIZAÇÃO MUNDIAL DA SAÚDE, 2016).

Vê-se que o bullying enquadra-se perfeitamente no conceito de violência adotado pela OMS, possuindo, todavia, características que o distinguem de outras formas de violência. Com efeito, o bullying define-se como uma agressão física, psicológica, verbal, moral, sexual ou virtual, praticada por uma ou mais pessoas contra uma mesma vítima, de forma repetitiva e prolongada, sem motivo aparente, com base em relação desigual de poder, dificultando a defesa da vítima e provocando-lhe sequelas, tais como doenças psíquicas, físicas (psicossomáticas), desordem pessoal e profissional, além de refletir na qualidade e finalidade do processo educativo, na sociedade e na saúde pública (ALKIMIN, 2011, p. 23).

Como se disse, o conceito de violência altera-se conforme o momento histórico e o contexto social em que inseridos os personagens da injusta agressão. A retomada dessa premissa mostra-se crucial ao entendimento do fenômeno do cyberbullying, que representa o já conhecido bullying com as peculiaridades decorrentes de sua inserção no espaço virtual. Assim, o cyberbullying é a agressão veiculada por meio de novas tecnologias de informação e de comunicação, notadamente por meio da internet (emails, chats, jogos virtuais, redes sociais, etc.) e de smartphones (envio de mensagens, ligações, fotos digitais, etc.) que visam à perseguição e intimidação da vítima.

O termo cyberbullying foi criado pelo pesquisador e educador canadense Bill Belsey, Presidente da Bullying.org, uma organização educacional destinada à prevenção do bullying mediante educação e conscientização e também criador do primeiro sítio sobre cyberbullying (www.cyberbullying.ca), que oferece cursos online destinados a pais e educadores. Para o renomado autor, cyberbullying involves the use of information and communication Technologies to support deliberate, repeated, and hostile behavior by na individual or group, wich is intended to harm others (BELSEY, 2019). BELSEY, ainda, faz o importante alerta:

Cyberbullying is also different in that it is a particularly cowardly form of bullying. Cyberbullies can more easily hide behind the anonymity that the Internet can provide.

Cyberbullies can communicate their hurtful messages to a very wide audience with remarkable speed.

Cyberbullying does not provide any tangible feedback about the consequences of using information technologies to cyberbully others. Cyberbullies do not have to own their actions, as it is usually very difficult to identify cyberbullies, so they do not fear being punished for their actions.

$[\ldots]$

In most cases, cyberbullies know their victims, but their victims may not know their cyberbullies, the aggressors may or may not bully their 
victims through physical, verbal, emotional or psychological means that are more easily identified.

With the advent of mobile, wireless Internet access, communications have become more ubiquitous. As a result, Cyberbullying can happen any time and any place and for many children, home is no linger a refuge from negative peer pressure such as bullying (BELSEY, 2019).

O conhecido bullying, portanto, com os requintes das avançadas tecnologias de informação e comunicação, demanda observação acurada e cautelosa, pois se desdobra em facetas antes inimagináveis, trazendo consequências, no que diz com a extensão do dano, por vezes, irreparáveis. Com efeito, no cenário virtual, a menção ao termo bull, que faz parte da etimologia da palavra, à qual acrescentou-se o prefixo cyber, não diz necessariamente com a compleição física ou com a expressão corporal do agressor, já denominado tirano, valentão ou brigão. $\mathrm{O}$ agressor virtual não precisa ser o mais forte, tampouco ser intrépido ou ousado; não precisa, ainda, ser extrovertido ou desinibido o bastante para falar em público, basta que tenha, outrossim, acesso à internet, por exemplo.

A seguir, para melhor compreensão das peculiaridades do fenômeno da violência virtual, passa-se à análise dos personagens comumente envolvidos no cyberbullying.

\subsection{Cyberbullying e seus personagens: peculiaridades}

MELO (2011. p. 34-37), de forma muito didática, esclarece que a tipologia dos personagens do bullying tradicional pode ser mantida, observadas as peculiaridades do espaço virtual que desvelam, necessariamente, traços característicos, dentre os quais além dos anteriormente citados - o anonimato e a fugacidade de alguns meios, fator encorajador para muitos agressores virtuais. Pela clareza da classificação sugerida, adota-se, nas linhas seguintes referida taxinomia. Para o autor, os personagens do cyberbullying são: (a) vítima virtual; (b) agressor virtual; (c) espectadores virtuais e (d) espectadores reais da agressão virtual (MELO, 2011, p. 34-37).

A vítima virtual pode ser qualquer pessoa; isto é, qualquer indivíduo, potencialmente, pode ser vítima de cyberbullying, não existindo um perfil específico. Outrossim, existe maior propensão a incautos, ingênuos ou imprudentes de transformarem-se em vítimas, pois tendem a, voluntariamente, promoverem autoexposição inadequada na plataforma virtual, como é o caso de crianças ou pessoas ainda não habituadas aos ardis da internet. Ou seja, qualquer pessoa pode receber emails com conteúdos indesejados, pode facilitar aos crakers acesso a informações pessoais que estejam armazenadas em seus computadores (WIKIPEDIA, 2016), deparar-se com montagens de suas fotos no mundo virtual ou mesmo com agressões de ordem pessoal perpetradas contra si, seja por pessoas identificadas ou por anônimos.

O agressor virtual, por sua vez, é quem se utiliza de forma mal-intencionada das tecnologias de informação e de comunicação para intimidar, aterrorizar, perseguir, 
tiranizar ou agredir a outrem. Da mesma forma, não há um perfil de agressores virtuais que, via de regra, escondem-se atrás do anonimato.

Os espectadores do bullying virtual, por seu turno, podem ser virtuais ou reais. Os primeiros são os frequentadores de determinado ambiente virtual no qual se perpetrou a agressão, dela tomando conhecimento. Podem ser pessoas que fazem parte de uma mesma comunidade virtual e que leram mensagens desonrosas ou ultrajantes direcionadas contra uma vítima, de seu convívio social ou não. Os expectadores reais, por outro lado, são testemunhas físicas de uma agressão virtual, ou seja, assistem o envio de conteúdos difamatórios por qualquer mídia: e-mail, redes sociais, telefone, etc.

Ainda no que se refere aos espectadores, reais ou virtuais, convém mencionar que podem adotar posturas diversas, assim classificadas: (a) passivos: não concordam com a postagem difamatória, mas também nada fazem, provavelmente por temerem ser as próximas vítimas; (b) ativos: apoiam a conduta do agressor, incentivando-o e (c) neutros: indiferentes, não se importam, apresentam, por assim dizer, uma espécie de anestesia emocional.

Como se pode observar, a prática do bullying virtual possui personagens específicos, que contaminam não apenas o ambiente virtual como todo o entorno social. Com efeito, quando ocorre uma agressão virtual, não apenas a vítima, diretamente lesada, é atingida, mas todas as pessoas que compõem o ambiente virtual e que não podem ser separadas da pessoa que compõe o mundo real.

As causas que motivam os agressores virtuais, ao que parece, não diferem de quaisquer outras que sirvam como pano de fundo para diferentes tipos de violência. Não há como dissociar as agressões, compreendidas como exteriorizações de comportamentos antissociais, intolerantes e preconceituosos do contexto sociocultural do agressor. Nessa linha, o cyberbullying é um reflexo perfeito dessa cultura embasada na insensibilidade interpessoal e na total ausência de responsabilidade e solidariedade coletiva (SILVA, 2010). Ademais, preconceitos, estigmas e discriminações agudam a intolerância dos atores sociais, promovendo efeitos danosos ao bom convívio social (BRITO FILHO, 2013, p. 937-938).

Conhecidos os conceitos de bullying e cyberbullying, é importante dizer que esse tipo de conduta ocorre nos mais variados ambientes sociais, dentre os quais o laboral, tema central dessa pesquisa. $\mathrm{O}$ termo bullying que, a princípio, era utilizado para referirse aos ambientes escolares, "democratizou-se", avançando para os demais agrupamentos humanos e, quando cunhada a expressão cyberbullying, já era francamente reconhecido e aplicado para além dos muros escolares.

A preocupação com a prática nefasta e com a sua prevenção e combate levou o Legislativo Brasileiro à promulgação da Lei $\mathrm{n}^{\circ}$. 13.185/15, a seguir examinada, que se aplica, como decorrência lógica do já explanado, para além dos estabelecimentos de ensino, a outras organizações coletivas, como empresas, por exemplo.

\section{Análise da Lei no ${ }^{0}$ 13.185/2015: programa de combate à intimidação sistemática}


Recentemente, foi promulgada no Brasil a Lei $n^{\circ} 13.185 / 2015$, que instituiu o programa de combate à intimidação sistemática, tratada como sinônimo de bullying. $\mathrm{O}$ art. $1^{\circ}$ da referida Lei conceitua o bullying como todo ato de violência física ou psicológica, intencional e repetitivo que ocorre sem motivação evidente, praticado por indivíduo ou grupo, contra uma ou mais pessoas, com o objetivo de intimidá-la ou agredi-la, causando dor e angústia à vítima, em uma relação de desequilíbrio de poder entre as partes envolvidas. Vê-se que o conceito desenhado pela lei traz verdadeira similitude com o já explanado nesta pesquisa. Enfatiza-se que a intimidação sistemática pode se dar por meio de violência física ou psicológica, ou seja, admite alargado espectro semântico, sendo que a chamada violência psicológica pode ocorrer das mais variadas formas, o que nos remete, novamente, à natureza multicausal da violência.

$\mathrm{O}$ art. $2^{\circ}$ da Lei $\mathrm{n}^{\circ} 13.185 / 2015$ vai enumerar uma lista de condutas que podem enquadrar-se na moldura elástica da violência, revelada em atos de intimidação, humilhação ou discriminação, tais como ataques físicos, insultos pessoais, comentários depreciativos sistemáticos, apelidos pejorativos, ameaças, grafites insultosos, expressões preconceituosas, isolamento social consciente e premeditado e pilhérias. Impende destacar, outrossim, que a lista é apenas exemplificativa, em face do alargado e já comentado conceito multicausal de violência, que se modifica ao sabor do contexto histórico, cultural e social em que inseridos agressor e vítima. No art. $3^{\circ}$, a Lei ${ }^{\circ}$. 13.185/2015 vai apresentar taxinomia quanto a possíveis formas de intimidação sistemática, tais como: verbal, moral, sexual, social, psicológica, físico, material e virtual, voltando a exemplificar cada uma delas com condutas tidas como intimidação sistemática ou bullying.

Para caracterizar-se o bullying, conforme a legislação brasileira, é preciso que esta violência seja intencional ou dolosa; o conceito, neste ponto, restringe o âmbito de aplicação da lei anti-bullying, porquanto condutas jocosas, por exemplo, sem intenção de ferir, ou condutas culposas, que atinjam direta ou indiretamente a vítima, mas que não tenham sido objetivamente contra ela desferidas, estão excluídas do contorno do $\S$ $1^{\circ}$ do art. $1^{\circ}$ da Lei $n^{\circ} .13 .185 / 2015$.

A conduta, ainda, deve ser repetitiva, reiterada, repisada. $\mathrm{O}$ autor da ofensa nela deve insistir perante o mesmo ofendido ou grupo de pessoas, ainda que sem motivação aparente, sempre no intuito de amedrontar, ou agredir, causando dor e angústia, surrupiando a paz da vítima, de modo a provocar-lhe danos de ordem física e moral, contextualizados em uma relação desigual de poder.

A Lei $\mathrm{n}^{\circ}$. 13.185/15 expressamente menciona, no parágrafo único do art. $2^{\circ}$, o cyberbullying, ao asseverar que há intimidação sistemática na rede mundial de computadores, quando neste ambiente e, mediante o uso de recursos que lhe são próprios, o agressor virtual depreciar, incitar violência, adulterar fotos e dados pessoais objetivando o constrangimento psicossocial da vítima. Novamente, ressalta-se que a natureza da lista só pode ser exemplificativa, pois não é dado ao legislador, ainda mais quando se trata de tecnologias, prever todas as formas pelas quais pessoas malintencionadas possam agir em detrimento de outras.

O programa de combate à intimidação sistemática, a dar-se em todo o território nacional, objetiva prevenir e combater a prática de bullying, capacitando docentes e equipes pedagógicas à implementação de ações que visam discutir, prevenir, orientar e 
solucionar o problema e, neste intento, orientar pais, familiares e responsáveis diante da identificação de vítimas e de agressores. Para tanto, busca integrar os meios de comunicação em massa às escolas e à sociedade, promovendo a conscientização, a cidadania, a capacidade empática e o respeito a terceiros, indispensáveis em uma sociedade que se pretenda pluralista, inclusiva e tolerante. Ainda dentro deste espírito de cooperação e conscientização, deve-se evitar, tanto quanto possível, a punição dos agressores, em detrimento da utilização de meios alternativos que promovam a responsabilização e consequente retração do comportamento hostil.

Por fim, importa ressaltar, que embora a lei faça, predominantemente, menção aos estabelecimentos de ensino, não estão excluídos outros órgãos e entidades, conforme se verifica da leitura do caput do art. $5^{\circ}$, que estabelece o dever às escolas e demais estabelecimentos de ensino, além de clubes e agremiações recreativas, de assegurar medidas de prevenção, diagnose e combate à violência e à intimidação sistemática. E esse compromisso verificar-se-á no art. $6^{\circ}$, que prevê a produção e publicação de relatórios bimestrais das ocorrências de bullying nos estados e municípios, com o fim de melhoramento do planejamento das ações de combate.

A temática parece bastante afeta ao ambiente escolar e, por isto, facilmente analisável nas relações pedagógicas e trabalhistas deste cenário. No entanto, impende, após o estudo dos principais conceitos relacionados ao bullying e ao cyberbullying, bem como da novel Lei de Combate à Intimidação Sistemática, estender e ampliar a investigação e apreciar como o tema vem sendo tratado pela jurisprudência trabalhista, mesmo que sob outras nomenclaturas, especialmente como Assédio Moral ou Assédio Moral Virtual, nas relações trabalhistas lato senso.

\section{O bullying e o cyberbullying no cenário trabalhista}

Pesquisas realizadas nos sítios eletrônicos do Tribunal Superior do Trabalho TST e tribunais regionais do trabalho do país elencam enorme rol de julgados, cuja conduta ensejadora do dever de indenizar ampara-se em fatos perfeitamente enquadráveis na figura do bullying. Todavia, no entorno trabalhista, tais condutas recebem os designativos de assédio moral ou assédio sexual, sendo indenizadas a título de danos morais.

E por assédio moral, na doutrina de Maurício Godinho Delgado, deve-se entender a conduta reiterada seguida pelo sujeito ativo no sentido de desgastar o equilíbrio emocional do sujeito passivo, por meio de atos, palavras, gestos e silêncios significativos que visem ao enfraquecimento e diminuição da autoestima da vítima ou outra forma de desequilíbrio e tensão emocional graves (DELGADO, 2013, p. 1262).

Embora esse tipo de conduta não seja novidade nos ambientes laborais, ou mesmo familiares e escolares, destaca o já citado autor que a figura foi recentemente apreendida na doutrina e jurisprudência, estimulada por uma percepção mais cuidadosa da potencial dinâmica ilícita vivida na relação de emprego, que não foi alvo de maior atenção antes da Constituição de 1988 (DELGADO, 2013, p. 1262).

O assédio moral, no âmbito da relação de emprego, ocorre mais comumente na forma vertical descendente, ou seja, de superior hierárquico para o inferior, podendo 
ainda acontecer de forma ascendente - inferior contra superior - e, também, horizontalmente, isto é, entre colegas.

$\mathrm{Na}$ hipótese de assédio moral vertical descendente, é possível ao empregado rescindir indiretamente o contrato de trabalho por justa causa do empregador, com amparo no art. 483 da CLT. É preciso referir que o rol do art. 483 não traz a figura do assédio moral, porém tal hipótese pode ser enquadrada em mais de uma das alíneas do dispositivo, citando-se, exemplificativamente: exigência de serviços do empregado superiores às suas forças, proibidos por lei, contrários aos bons costumes ou alheios ao contrato (alínea "a"), tratamento pelo empregador com rigor excessivo (alínea "b"), praticar o empregador ou seus prepostos ato lesivo contra a honra e a boa fama do empregado ou de membros de sua família (alínea "e"), o empregador ou seus prepostos ofenderem ao empregado fisicamente (alínea " $\mathrm{f}$ ") e o empregador reduzir o trabalho do empregado de forma a afetar sensivelmente o seu salário (alínea "g").

O empregador pode, em franco assédio moral, praticar qualquer uma das condutas acima listadas, tendo como pano de fundo postura abusiva, reiterada, violenta - física ou psicológica - com o fim de agredir determinado empregado ou grupo de empregados e, neste caso, além das verbas rescisórias pertinentes à rescisão indireta, caberá ao empregador o pagamento de indenização por danos morais (ou outra figura reparatória extrapatrimonial pertinente e possível) perpetrados em face do empregado.

Se o assédio moral for cometido entre colegas de trabalho, da mesma forma, embora inexista menção expressa ao instituto no art. 482, da CLT, é possível que reste configurado mediante a prática de condutas previstas em determinadas alíneas do dispositivo, como é a hipótese do mau procedimento (alínea " $b$, final), ato de indisciplina ou de insubordinação - neste último caso, é bem verdade, poder-se-ia cogitar de um assédio vertical ascendente (alínea h") - ato lesivo contra a honra de boa fama praticado no serviço e ofensas físicas desferidas a colega de trabalho.

Importa referir, ademais, que em algumas situações é mais difícil a percepção pelo empregador do assédio ocorrente entre colegas de trabalho, o que pode vir a lhe atenuar a responsabilidade; este fato, porém, não lhe isenta totalmente de responder pelo assédio ocorrido nas dependências do seu estabelecimento, porquanto cabe a ele, por força do que lhe determina o art. 157 da CLT, proporcionar aos seus empregados ambiente hígido de trabalho.

A contribuir para a atenuação de eventual culpa do empregador, ainda, poderia ele alegar a sua "pré-ocupação" em construir um ambiente laboral de relações éticas, com códigos de conduta claros e objetivos, canais de denúncia funcionais e efetivos, o que só reforça a atual tendência corporativa de investimento em Compliance e técnicas de Responsabilidade Social Empresarial. Evidentemente, todas essas questões serão apreciadas e delineadas pela casuística, de modo a refletir, diretamente, no grau de responsabilidade do empregador que, pensa-se, não deve ser, a priori, objetiva.

HIRIGOYEN, pesquisadora do tema, destaca, todavia, que nem todas as pessoas que se dizem assediadas realmente o são. Inicialmente, elucida que o assédio moral não se confunde com estresse profissional - estado biológico provocado por determinadas situações sociais e sociopsicológicas - que, no mais das vezes, decorre de sobrecargas e más condições de trabalho. Esclarece a autora que a fase de assédio moral começa quando a pessoa que é o alvo percebe a má intenção de que é objeto, isto é, quando as 
críticas a seu trabalho se tornam maldosas e as atitudes e palavras se tornam injuriosas (HIRIGOYEN, 2015, p. 19-36).

Da mesma forma, o assédio moral não se confunde com a gestão por injúria, que é um tipo despótico de comportamento de certos administradores, despreparados, que submetem empregados à terrível pressão, injuriando-os e insultando-os. Enquanto o assédio moral é velado, a gestão por injúria é notada por todos; enquanto o assédio dirige-se contra uma pessoa ou grupo, esta forma deplorável de gestão não escolhe vítimas específicas, senão tensiona todo o ambiente laboral. Assim, assédio moral não se confunde com estresse, gestão por injúria, agressões pontuais, más condições de trabalho e imposições profissionais (HIRIGOYEN, 2013); porém, o assédio moral pode configurar-se com a imposição de outros elementos agregados a essas condições, quando houver intenção de ferir, mediante condutas reiteradas fitando desestabilizar o equilíbrio emocional da vítima (HIRIGOYEN, 2015, p. 19-36).

No que se refere ao bullying, a mesma pesquisadora destaca que, inicialmente, o termo não fazia parte do universo do direito do trabalho. Falava-se de bullying, outrossim, para descrever humilhações e vexames entre crianças e adolescentes em estabelecimentos de ensino. Posteriormente, o termo estendeu-se para abarcar as agressões havidas nos exércitos, em práticas desportivas e na vida familiar, até ingressar no mundo do trabalho. Informa HIRIGOYEN que somente em 1984 o termo foi introduzido na psicologia do trabalho por Folkman Lazarus, de modo a albergar as condutas descritas como assédio moral ou assédio sexual, tendo, portanto, ampla acepção desde chacotas a isolamentos até condutas abusivas de conotação sexual ou agressões físicas (HIRIGOYEN, 2015, p. 79-80).

E por falar em assédio sexual, este é definido por Maurício Godinho Delgado como a conduta de importunação reiterada e maliciosa, explícita ou não, com interesse e conotações sexuais, de uma pessoa física em relação a outra (DELGADO, 2013, p. 1264).Vê-se, portanto, que os elementos são os mesmos que formam o constructo do assédio moral, com o requinte da conotação sexual da conduta do agressor. Assim, caracterizam o assédio sexual, exemplificativamente, condutas que envolvam contato físico indesejado, propostas e pedidos sexuais mal recebidos, uso de linguagem sexualmente ofensiva, constantes convites para encontros amorosos, ainda que a vítima já os tenha recusado inúmeras vezes, ameaças de punição pela recusa desses pedidos, etc.

Da mesma forma, não há previsão expressa nas alíneas dos artigos 482 e 483 da CLT quanto ao assédio sexual, socorrendo-se, a vítima, das previsões das alíneas "b" do art. 482 e "e" do art. 483, conforme o caso, para a salvaguarda do seu direito de rescisão contratual com fundamento na justa causa, bem como à indenização correspondente ao dano moral sofrido, embasada nos artigos $5^{\circ}, \mathrm{V}$, da Constituição Federal e artigos 186 e 927, do Código Civil.

HIRIGOYEN alerta que o assédio sexual não é mais do que uma evolução do assédio moral. Destaca que nos dois casos, fala-se de humilhação e, nesse intento, busca-se o íntimo da vítima. Pergunta a autora: o que há de mais íntimo do que o sexo? O que há de mais difícil de ser manifesto do que uma atmosfera sexista ou hostil? Desta forma, sobreleva que o assédio sexual nas relações trabalhistas envolve não apenas a chantagem para o emprego como o clima de trabalho sexista, hostil e ofensivo (HIRIGOYEN, 2015, p. 99-103). 
A despeito da similitude entre o assédio moral e sexual, com a inclusão, conforme já dito, da conotação sexual no segundo caso, há algumas nuances que merecem destaque. Com efeito, enquanto no assédio moral o objetivo do agressor é destruir a vítima, no assédio sexual, pode não ser somente este, senão o intento de possui-la. O assédio sexual é fruto do desejo, podendo ser caracterizado por um único ato, a depender da gravidade deste, pressupondo uma diferença hierárquica. Por seu turno, conforme já visto, o assédio moral só finda quando produz danos psíquicos à vítima, mediante um comportamento agressivo reiterado, no mais das vezes fruto da inveja, dispensando a diferença hierárquica.

Quanto à relação entre assédio e gênero, convém destacar que o estudo realizado pela renomada autora demonstrou uma clara diferença entre a distribuição dos sexos: $70 \%$ de mulheres e $30 \%$ de homens. Estes números, todavia, diferem dos resultados obtidos em pesquisa realizada em Estrasburgo, na qual chegou-se ao resultado percentual de $43,5 \%$ de mulheres assediadas contra $56,5 \%$ de homens assediados, e de pesquisa realizada na Suécia, segundo a qual $55 \%$ das mulheres eram afetadas, ao passo que $45 \%$ dos homens eram as vítimas. $\mathrm{O}$ resultado das pesquisas, por certo, identifica-se com o contexto sociocultural dos países examinados. Os países escandinavos e a Alemanha manifestam real preocupação com a igualdade entre homens e mulheres e isso se reflete nos percentuais destacados. Por sua vez, os países latinos apresentam percentuais mais elevados de assédio contra mulheres, especialmente do tipo vertical descendente. Ademais, em países como Itália, Espanha e na América Latina (citados pela autora), muitos homens consideram que cada mulher que trabalha é culpada por um desempregado entre os homens (HIRIGOYEN, 2015, p. 99).

Assim, os conhecidos, há longa data, assédios moral e sexual pela jurisprudência trabalhista brasileira são figuras que podem ser enquadradas no grande "guarda-chuva" denominado bullying e, quando essas agressões envolverem o ambiente virtual ou tecnologias de informação e comunicação (ex.: email, facebook, instagram, grupos de trabalho no whatsapp, etc.), na mais nova e sofisticada forma de bullying denominada cyberbullying. Portanto, a ausência expressa aos termos grifados não significa inexistência de reconhecimento pela jurisprudência do dever de indenizar, senão o reconhecimento mediante nomenclatura distinta e há tempo acomodada no linguajar jurídico.

\section{A responsabilidade do empregador pelo bullying e cyberbullying}

Cabe perquirir, ainda, da responsabilidade do empregador, nos casos de assédio moral e sexual em ambiente laboral, contidos no grande conceito de bullying ou, ainda, quando tais práticas se derem em ambiente virtual ou mediante o uso de ferramentas ligadas às tecnologias de informação e comunicação, caracterizando-se, portanto, o cyberbullying.

É preciso destacar que em matéria de responsabilidade civil, o Código de 2002, usado subsidiariamente em seara laboral, adotou a teoria da responsabilidade na modalidade de risco ocupacional; é dizer, assume o empregador o risco pelo tratamento dispensado aos seus empregados, sendo devedor de um ambiente laboral hígido e 
adequado ao desempenho das atividades exigidas. Esse posicionamento, vale dizer, é defensável a partir da leitura conjunta dos artigos 927, 186 e 187 do Código Civil e, note-se, neste caso, a responsabilidade do empregador é objetiva.

Ocorre, todavia, como anteriormente advogado, que em determinadas situações essa responsabilidade pode ser atenuada, sendo razoável perfilhar-se interpretação neste sentido no caso de empresas que possuam canais abertos de reclamações de seus empregados, ou que participem de programas de prevenção e conscientização dos seus empregados e mesmo sócios no combate a qualquer forma de bullying, real ou virtual, fiscalizando-os. Ou seja, a casuística irá delimitar o grau de responsabilidade do empregador, que não deve ser o mesmo, para o patrão totalmente omisso ou assediador, comparativamente ao empregador que mantém setor específico e seguro de reporte pelos empregados desse tipo de situação e que investe na qualidade do meio ambiente laboral.

É de fundamental relevo mencionar, que a partir da já examinada Lei de Combate à Intimação Sistemática (bullying), Lei $\mathrm{n}^{\circ} 13.185 / 2015$, foi possível vislumbrar para a empresa um dever que já lhe cabia a partir de uma interpretação pautada na sua função social, mas que agora se torna expresso, no sentido de promover medidas de conscientização, prevenção e combate a todos os tipos de violência, bem como de monitorar os casos de bullying dentro do seu estabelecimento mediante a produção de relatórios bimestrais de ocorrências de intimidação sistemática (art. $6^{\circ}$ ), os quais terão fundamental importância no planejamento das ações voltadas ao seu combate em todos os níveis da sociedade.

Por todo o exposto, certos da ocorrência de bullying e de cyberbullying nos mais diversos ambientes coletivos, dentre os quais os trabalhistas, bem como do reconhecimento dessas modalidades de agressão mediante as denominações de dano moral e sexual pela jurisprudência trabalhista, entende-se pertinente e adequada a aplicação também às relações de trabalho da Lei de Combate à Intimidação Sistemática (Lei $\left.\mathrm{n}^{\mathrm{o}} 13.185 / 15\right)$, por reforçar o dever de toda a sociedade em prevenir, conscientizar e combater tal prática, bem como por envolver um verdadeiro programa de combate, para o qual os relatórios enviados pelos mais diversos estabelecimentos, representam importante ferramenta de monitoramento, controle e planejamento contra o bullying e o cyberbullying em nossa sociedade, que pretende, entre outros objetivos, ser pluralista e inclusiva.

\section{Responsabilidade do empregador na lei da reforma trabalhista}

A Lei $n^{\circ}$. 13.467/2017 inaugura nova fase no Direito Material do Trabalho relativamente à Responsabilidade Civil. Importa referir que o sistema de "empréstimo" dos dispositivos do Código Civil (pelo favor legal do artigo $8^{\circ}$ da CLT ) foi suprimido por opção legal, nos termos do Art. 233-A da Lei.

Em apertada síntese, em uma relação de trabalho, ao lado dos danos patrimoniais (tradicionalmente resolvíveis via recomposição das perdas e danos e dos lucros cessantes) e quiçá somados a estes, podem existir os danos extrapatrimoniais. Justamente estes são decorrência clássica das condutas estudadas neste artigo (bullying, 
cyberbullying, assédio moral, assédio sexual, etc.) e, no novo arranjo da Consolidação das Leis do Trabalho, ganharam espaço privilegiado, com título próprio:

\section{TÍTULO II-A DO DANO EXTRAPATRIMONIAL}

Art. 223-A. Aplicam-se à reparação de danos de natureza extrapatrimonial decorrentes da relação de trabalho apenas os dispositivos deste Título.'

Art. 223-B. Causa dano de natureza extrapatrimonial a ação ou omissão que ofenda a esfera moral ou existencial da pessoa física ou jurídica, as quais são as titulares exclusivas do direito à reparação.

Art. 223-C. A honra, a imagem, a intimidade, a liberdade de ação, a autoestima, a sexualidade, a saúde, o lazer e a integridade física são os bens juridicamente tutelados inerentes à pessoa física.

Art. 223-D. A imagem, a marca, o nome, o segredo empresarial e o sigilo da correspondência são bens juridicamente tutelados inerentes à pessoa jurídica.

Art. 223-E. São responsáveis pelo dano extrapatrimonial todos os que tenham colaborado para a ofensa ao bem jurídico tutelado, na proporção da ação ou da omissão.

Art. 223-F. A reparação por danos extrapatrimoniais pode ser pedida cumulativamente com a indenização por danos materiais decorrentes do mesmo ato lesivo.

$\S 1^{\circ}$ Se houver cumulação de pedidos, o juízo, ao proferir a decisão, discriminará os valores das indenizações a título de danos patrimoniais e das reparações por danos de natureza extrapatrimonial.

$\S 2^{\circ}$ A composição das perdas e danos, assim compreendidos os lucros cessantes e os danos emergentes, não interfere na avaliação dos danos extrapatrimoniais.

Art. 223-G. Ao apreciar o pedido, o juízo considerará:

I - a natureza do bem jurídico tutelado;

II - a intensidade do sofrimento ou da humilhação;

III - a possibilidade de superação física ou psicológica;

IV - os reflexos pessoais e sociais da ação ou da omissão;

V - a extensão e a duração dos efeitos da ofensa;

VI - as condições em que ocorreu a ofensa ou o prejuízo moral;

VII - o grau de dolo ou culpa;

VIII - a ocorrência de retratação espontânea;

IX - o esforço efetivo para minimizar a ofensa; 
X - o perdão, tácito ou expresso;

XI - a situação social e econômica das partes envolvidas;

XII - o grau de publicidade da ofensa.

$\S 1^{\circ}$ Se julgar procedente o pedido, o juízo fixará a indenização a ser paga, a cada um dos ofendidos, em um dos seguintes parâmetros, vedada a acumulação:

I - ofensa de natureza leve, até três vezes o último salário contratual do ofendido;

II - ofensa de natureza média, até cinco vezes o último salário contratual do ofendido;

III - ofensa de natureza grave, até vinte vezes o último salário contratual do ofendido;

IV - ofensa de natureza gravíssima, até cinquenta vezes o último salário contratual do ofendido.

$[\ldots]$

$\S 2^{\circ}$ Se o ofendido for pessoa jurídica, a indenização será fixada com observância dos mesmos parâmetros estabelecidos no $\S 1^{\circ}$ deste artigo, mas em relação ao salário contratual do ofensor.

$\S 3^{\circ} \mathrm{Na}$ reincidência entre partes idênticas, o juízo poderá elevar ao dobro o valor da indenização (BRASIL, 2017, grifo nosso).

Embora o texto legal seja aparentemente didático, acrescenta-se que, na lição de PORTO E PEREIRA (2017, P. 161), por danos extrapatrimoniais, deve-se compreender, "toda lesão a um interesse protegido pelo ordenamento jurídico e que tem por objeto uma utilidade sem expressão monetária no mercado", quiçá por isto o legislador tenha pretendido elencar, acredita-se que em intenção exemplificativa, "a honra, a imagem, a intimidade, a liberdade de ação, a autoestima, a sexualidade, a saúde, o lazer e a integridade física, além da imagem, a marca, o nome, o segredo empresarial e o sigilo da correspondência" como bens albergados sob este manto (vide artigos 233-C e 233-D, respectivamente).

Algumas dúvidas devem ser ainda afastadas via interpretação jurisprudencial, como por exemplo, o cabimento, ou não, das demandas por danos indiretos (ou danos em ricochete) em face do teor do artigo 233-B, ou seja, se os parentes da vítima de cyberbullying, uma vez em vigor a Reforma Trabalhista, ainda poderiam demandar na Justiça Especializada do Trabalho contra a empregadora da vítima e do agressor, buscando a reparação pelos danos que os atos intimidatórios, indiretamente, lhes houvessem ocasionado.

A não cumulatividade entre danos extrapatrimoniais (Art. $233-\mathrm{G} \S 1^{\circ}$ ) é outra questão a ser enfrentada, uma vez que atualmente é pacífica a compreensão da independência entre danos extrapatrimoniais estéticos e morais, por exemplo, daí decorrendo sua possível cumulação. Para além disto, a modulação da condenação (incisos I, II e III) não tem agradado a muitos, prometendo gerar muita polêmica ainda. 
Serão novos tempos para a Responsabilidade Civil nas relações trabalhistas, que exigirão de operadores e intérpretes muita calma, serenidade e prudência.

\section{Considerações finais}

Diante da amostra humana observada (seres urbanos, jovens, estudantes e/ou trabalhadores) é forçoso admitir uma nova, ou ao menos dupla, existência. Ao lado ou confusamente à existência presencial, fortemente, há a existência virtual, a gerar efeitos tão concretos quanto àquela. A vida em ambientes virtuais ou o trabalho com ferramentas digitais é o cotidiano destas pessoas que fazem seus relacionamentos e comunicações, por vezes, majoritária ou exclusivamente, via canais eletrônicos e redes sociais.

Não é de se estranhar que também os conflitos e desvios de conduta ali também ocorram e que, inclusive, fenômenos como o bullying ou o assédio moral ali igualmente acabem acontecendo. No entanto, o que se percebe, é que o efeito nocivo de tais fenômenos, através dos canais e ambientes digitais, se multiplica de forma ilimitada e descontrolada.

O Cyberbullying apoia-se nas características peculiares de seu meio, tais como o anonimato e a fugacidade de algumas ferramentas, que acabam encorajando alguns agressores. Ademais, a veloz multiplicação da informação intimidatória, aliada à ineficácia dos meios de retirada compulsória dos dados da internet gera efeitos danosos devastadores nas vítimas, o que compõe um quadro muito mais complexo do que o bullying.

A Lei $n^{\circ} 13.185 / 2015$ - Programa de Combate à Intimidação Sistemática anuncia avanço importante na prevenção e combate à violência intimidatória, presencial ou virtual, especialmente porque inaugura novos paradigmas, como o combate via despenalização e o levantamento de dados constante, vindos diretamente dos espaços sociais (escolas, no caso) que passam a colaborar compulsoriamente. Sua ideia é ser programa de (re)educação e política pública permanente, que envolve especialmente os principais responsáveis pela educação de crianças, jovens e adultos. Entende-se que sua principal utilidade à comunidade, alargando-se sua utilização para além dos estabelecimentos educativos e afins, seria a possibilidade de um monitoramento mais próximo e concreto das "práticas intimidatórias", tornando obrigatório a todo e qualquer estabelecimento o fornecimento de relatórios nesse sentido, onde se informasse a identificação dos casos e as práticas (não penalizatórias, frise-se) adotadas para sua correção, visando a prevenção de novos casos e a harmonização social.

Pelos contornos conceituais abrangentes que a legislação em comento trouxe, entendeu-se possível neste estudo advogar a extensão de sua aplicabilidade aos fenômenos já bastante estudados e corriqueiros nas lides trabalhistas (assédio moral ou, até mesmo ao assédio sexual), pelo que se realizaram as aproximações necessárias, doutrinária e jurisprudencialmente. 
Viu-se possível, por exemplo, acomodar as condutas de empregados e empregadores assediadores nos artigos 482 ou 483 da CLT, assim como viável aplicar, pelo menos, a teoria da responsabilidade subjetiva do empregador, em face do dever de manutenção da ambiência laboral equilibrada e saudável.

Foi necessário, no particular da reparação de danos, trazer à tona as alterações no sistema de Responsabilidade Civil, a atingir especialmente a questão dos danos extrapatrimoniais, criando microssistema dentro do Direito do Trabalho, com peculiaridades, no mínimo, interessantes. A criação de título específico aos danos extrapatrimoniais, inserido na Consolidação das Leis do Trabalho privilegia a matéria, mas longe de tornar mais claro o tema, chama à obra operadores e jurisconsultos: há muito o que esclarecer via doutrina e jurisprudência, desde a natureza do rol dos artigos 233-C e D (taxativo ou exemplificativo?) ao aparente fechamento das portas da Justiça Especializada do Trabalho às demandas por dano extrapatrimonial em ricochete.

Pois, cruzando com o problema cerne deste estudo, atingem-se contornos ainda mais complexos: para além da reparação, exigem-se do empregador posturas preventivas que, em ambiente laboral e/ou relacional virtual se tornam difíceis ou ineficazes, aliadas ao fato de que o agressor, de certa forma, sente-se estimulado pelo anonimato, além do que os efeitos da agressão são potencializados pela velocidade e hiperconexão das redes sociais.

É nesse sentido que adotar ações similares às recomendadas pela Lei $\mathrm{n}^{\circ}$ 13.185/2015 (Lei Antibullying) passa a ser importante. Exigir que os estabelecimentos monitorem e, compulsoriamente informem aos órgãos públicos os casos de intimidação sistemática (bullying, cyberbullying, assédio moral, assédio sexual ou qualquer outra forma de violência enquadrável no conceito legal elastecido) é, no fundo, uma política pública de controle, combate e prevenção ao fenômeno de degradação relacional tratado na lei.

Saber onde ocorre, quem pratica, quem sofre e que medidas foram tomadas em cada caso é imprescindível à saúde coletiva e é disto que se fala, quando se fala de intimidação sistemática e de condutas humanas doentias e perversas, que fazem adoecer humanos, degradam ambientes e impedem o bom convívio.

É em razão disto que entidades privadas e poder público são chamados à responsabilidade pela Lei Antibullying e, no tocante ao âmbito trabalhista, não se pode cingir o debate ao singelo cálculo de perdas e danos. $\mathrm{O}$ debate da Responsabilidade Social Empresarial há muito impõe pensar na prevenção e, muito antes dela, na precaução como estratégia de gestão.

Assim, afigura-se singela, quiçá equivocada, a posição de que a Lei Antibullying não se aplica às relações trabalhistas em lato senso. Ao revés, seu escopo abrangente, com tarefas que vão além da mera sinalagmaticidade histórica e tradicional (empregadoempregador), deve passar a ser pauta e meta de gestores e órgãos de físcalização, integrando agendas, por exemplo, de setores empresariais dedicados ao Compliance, de Sindicatos profissionais e até do Ministério Público do Trabalho, todos envolvidos e comprometidos com mesmo objetivo: devolver a ética, a humanidade e a fraternidade às relações no ambiente de trabalho, seja ele presencial ou virtual. 


\section{Referências}

ALKIMIN, Maria Aparecida (org.). Bullying. Visão interdisciplinar. Campinas: Editora Alínea, 2011.

ALVES, Giovanni; MARTINEZ, Vinicio (org.). Dialética do Ciberespaço. Trabalho, tecnologia e política no capitalismo global. Bauru: Editora Document Arminda, 2002.

BELSEY, Bill. Cyberbullying. Disponível em: <http://www.cyberbullying.ca/pdf/Cyberbullying_Article_by_Bill_Belsey.pdf >. Acesso em: 20 nov. 2016.

BRASIL. CONSTITUIÇÃO DA REPÚBLICA FEDERATIVA DO BRASIL DE 1988. Constituição Federal. Disponível em: <http://www.planalto.gov.br/ccivil_03/Constituicao/Constituicao.htm>. Acesso em 20 nov. 2016.

DECRETO-LEI N ${ }^{\circ}$ 5.452, DE $1^{\circ}$ DE MAIO DE 1943. Consolidação das Leis do Trabalho. Disponível em: <http://www.planalto.gov.br/ccivil_03/decretolei/Del5452.htm>. Acesso em 20 nov. 2016.

LEI N ${ }^{\circ}$ 10.406, DE 10 DE JANEIRO DE 2002. Código Civil. Disponível em: <http://www.planalto.gov.br/ccivil_03/LEIS/2002/L10406.htm>. Acesso em 06 mar. 2018.

\section{Intimação Sistemática. $\quad$ Disponível} <http://www.planalto.gov.br/ccivil_03/_ato2015-2018/2015/lei/113185.htm>. Acesso em 06 mar. 2018.

LEI 13.467, DE 13 DE JULHO DE 2017. Disponível em: <http://www.planalto.gov.br/ccivil_03/_Ato2015-2018/2017/Lei/L13467.htm>. Acesso em 06 mar. 2018.

BRITO FILHO, José Claudio Monteiro de. Ação Afirmativa: alternativa eficaz para a busca da diversidade no trabalho pelo Ministério Público do Trabalho. In Estudos Aprofundados do MPT. Salvador: Editora Juspodvium, 2013.

DELGADO, Mauricio Godinho. Curso de Direito do Trabalho. 12 ed. São Paulo: LTR, 2013.

HIRIGOYEN, Marie-France. El Acoso Moral en el Trabajo: distinguir lo verdadero de lo falso. Barcelona: Paidós, 2013.

HIRIGOYEN, Marie-France. Assédio moral. A violência perversa no cotidiano. 15 ed. Rio de Janeiro: Bertrand Brasil, 2014. 
HIRIGOYEN, Marie-France. Mal-estar no trabalho. Redefinindo o assédio moral. 8 ed. Rio de Janeiro: Bertrand Brasil, 2015.

LÉVY, Pierre. O futuro da internet: em direção a uma ciberdemocracia. São Paulo: Paulus, 2010.

LIMA, Ana Maria de Albuquerque. Cyberbullying e outros riscos na internet. Despertando a atenção dos pais e professores. Rio de Janeiro: Wak Editora, 2011.

MELO, Josevaldo Araújo de. Ciberbullying. A violência vitual. 2 ed. Recife: Edupe, 2011.

ORGANIZAÇÃO MUNDIAL DA SAÚDE. Informe mundial sobre la violencia y la salud. Disponível em: <http://apps.who.int/iris/bitstream/10665/112670/1/9275315884_spa.pdf>. Acesso em: 20 nov. 2016.

PORTO, Lorena Vasconcelos; PEREIRA, Ricardo José Macêdo de Britto. A tutela coletiva do dano extrapatrimonial no direito do trabalho. In: Danos Extrapatrimoniais no Direito do Trabalho. São Paulo: Ltr, 2017.

ROCHA, Telma Brito. Cyberbullying. Ódio, violência virtual e profissão docente. Brasília: Liber livro, 2012.

SHARIFF, Shaheen. Ciberbullying. Questões e soluções para a escola, a sala de aula e a família. São Paulo: Editora Sênior, 2008.

SILVA, Ana Beatriz Barbosa. Bullying: Mentes perigosas nas escolas. Rio de Janeiro: Objetiva, 2010.

WIKIPEDIA. Cracker. Disponível em: <https://pt.wikipedia.org/wiki/Cracker>. Acesso em 20 nov. 2016. 